\title{
Quais os Impactos da Desaposentação? Um Estudo para as Aposentadorias por Tempo de Contribuição do Regime Geral de Previdência Social
}

\author{
Angelo José Zanella \\ Escola Superior de Administração e Gestão Strong (ESAGS) \\ Endereço: Av. Industrial, 1455 - Jardim Santo André/SP - Brasil \\ CEP: 09081-510 - E-mail: ajzanella@gmail.com \\ João Vinícius de França Carvalho \\ Professor (EPPEN/UNIFESP e ESAGS) \\ Endereço: Rua Angélica, 100 - Jardim das Flores, Osasco/SP - Brasil \\ CEP: 06110-295 - E-mail: jvfcarvalho@unifesp.br

\section{Luís Eduardo Afonso} \\ Professor - Faculdade de Economia, Administração e Contabilidade (FEA/USP) \\ Endereço: Av. Prof. Luciano Gualberto 908, FEA 3, Sala 215 - Butantã, São Paulo/ SP - Brasil \\ CEP: 05508-010 - E-mail: lafonso@usp.br \\ Recebido em 30 de julho de 2013. Aceito em 13 de junho de 2014.
}

\section{Resumo}

Este trabalho visa a avaliar os impactos da desaposentação, termo empregado quando um segurado do INSS se aposenta, mas se mantém no mercado de trabalho formal e pede recálculo do valor da aposentadoria, devido ao acréscimo no período contributivo. Há um trade off importante: quanto mais o segurado demorar em pedir a desaposentação, maior será o incremento no valor do benefício. Porém, o tempo de usufruto deste ganho será menor. Inversamente, quanto mais prematura a desaposentação, menor será o aumento no benefício e maior o período de desfrute. A fundamentação teórica baseia-se nos conceitos de justiça atuarial e neutralidade atuarial. Foram utilizados quatro indicadores usualmente adotados na literatura previdenciária: Taxa de Reposição, Taxa Interna de Retorno, Alíquota Necessária e Alíquota Efetiva. Os resultados evidenciam um período ótimo para a desaposentação: pelo menos 4,83 anos (homens) e 7,83 anos para (mulheres). Se a devolução do benefício for obrigatória antes do recálculo, não há vantagens na desaposentação.

\section{Palavras-Chave}

Previdência Social, Desaposentação, Aposentadoria, Justiça Atuarial

\begin{abstract}
This study aims to evaluate the impacts of re-retirement, a term used when an Brazilian insured INSS retires, but remains in the formal labor market, and asks recalculation of the pension benefit due to the increase in the contribution period. There is an important tradeoff: the more the insured take to ask re-retirement, the greater the increase in the value of the benefit. However, the time of enjoyment of this gain will be less. Conversely, the more premature re-retirement, the lower the effective increase in the
\end{abstract}


period and greater enjoyment. The theoretical framework is based on the concepts of actuarial justice and actuarial neutrality. Were employed four indicators used in the literature pension: Replacement Rate, Internal Rate of Return, Necessary Rate and Effective Rate. The results show an optimal period for re-retirement: at least 4.83 years (men) and 7.83 years for (women). If the return of the benefit is required before the recalculation, there is no advantage in re-retirement.

\section{Keywords}

Social Security, Re-retirement, Retirement, Actuarial Fairness

\section{JEL Classification}

H55, J26

\section{Introdução}

No Brasil, os trabalhadores formais do setor privado devem compulsoriamente contribuir ao Regime Geral de Previdência Social (RGPS) do Instituto Nacional do Seguro Social (INSS). Após 35 (30) anos de contribuição, no caso dos homens (mulheres) atingem a única condição mínima de elegibilidade para a obtenção de uma Aposentadoria por Tempo de Contribuição (ATC), paga mensalmente, de forma vitalícia. No final de 2012 havia 4.862 .215 benefícios de ATC emitidos, representando 18,7\% dos 26.032.855 benefícios em estoque do RGPS. Somente em 2012 foram concedidos 275.840 novas aposentadorias por tempo de contribuição. Devido a ATC ser o benefício de valor médio ( $\mathrm{R} \$ 1$ 1.357) mais elevado, representou pouco mais de $27,5 \%$ com benefícios previdenciários do RGPS.

O valor do benefício é calculado com base na média salarial do segurado e do Fator Previdenciário (maior detalhamento das formas de cálculo será apresentado na seção 3). Esta engenhosa fórmula foi criada em 1999 por meio da Lei 9.876 e tem por objetivo introduzir maior grau de equilíbrio atuarial à relação entre contribuições e benefícios. Sua lógica é bastante simples: visa a incentivar as pessoas a postergarem a aposentadoria, por meio da redução do valor do benefício daqueles que decidiram se aposentar mais cedo, desde que, obviamente cumpram o requisito mínimo de período contributivo.

Uma parcela não desprezível dos aposentados, mesmo recebendo o benefício previdenciário, continua no mercado de trabalho formal e contribuindo para o RGPS. Após alguns anos nessa situação, a idade 
do segurado para a aposentadoria e o tempo de contribuição são maiores e sua condição de elegibilidade, $a$ priori, se mantém. Diante disso, o segurado pede o recálculo do valor da aposentadoria. Ou seja, é como se solicitasse a revisão do benefício, com aumento do valor recebido. Este recálculo do benefício previdenciário, dado seu novo tempo de contribuição, é conhecido como desaposentação.

No RGPS há duas particularidades que acabam por incentivar de forma perversa a desaposentação. A primeira é o fato de os benefícios previdenciários não serem means tested, como ocorre, por exemplo, nos EUA. Isto significa que o valor do benefício previdenciário independe da existência de outras fontes de renda. Logo, o trabalhador tem um forte incentivo a se aposentar precocemente (de forma comparativa a outros países) por tempo de contribuição, continuar no mercado de trabalho formal e buscar posteriormente a desaposentação. Ou seja, durante alguns anos, usufrui-se da condição de ser ao mesmo tempo trabalhador e aposentado, o que vai contra a lógica dos sistemas previdenciários, particularmente os de repartição. Agindo desta maneira, o benefício previdenciário acaba funcionando, de forma bastante distorcida, como um seguro contra riscos inerentes ao mercado de trabalho, como o desemprego. Se o trabalhador já aposentado perder temporariamente o emprego, terá uma garantia de renda, de forma vitalícia e em prestações continuadas, dada pela previdência social. Desta maneira, está de certa forma, transferindo o risco de geração de renda para a entidade previdenciária, ao mesmo tempo em que procura obter, sem custos adicionais, ${ }^{l}$ a condição de pleitear a revisão do benefício previdenciário.

A segunda particularidade é a inexistência de idade mínima para obtenção da ATC. A única condição de elegibilidade para este benefício é o período contributivo mínimo. Como este requisito é bastante frouxo, pessoas ainda bastante jovens obtêm a ATC, mas não se retiram do mercado de trabalho. E, posteriormente, pleiteiam a desaposentação, objeto de estudo deste artigo. ${ }^{2}$

${ }^{1}$ O termo sem custos adicionais significa que se pleitear a desaposentação e for bem sucedido, obterá o bônus desta decisão. No entanto, se a desaposentação lhe for negada, não há nenhuma forma ônus associado.

2 É importante assinalar que este trabalho não se posiciona, como pode ser erroneamente inferido, de forma favorável à desaposentação. O objetivo é apenas abordar uma particularidade (ou de uma distorção, de acordo com o ponto de vista) de nosso sistema previdenciário, que leva a um determinado comportamento de otimização de valor presente da renda por parte dos segurados. Como tal, merece ser alvo de um estudo, que se imagina ser original na literatura nacional. 
Este trabalho tem quatro seções além desta introdução. A seção 2 trata do referencial teórico sobre o qual o tema da desaposentação se aplica. Na seção 3 é apresentado o modelo empregado no trabalho e os indicadores previdenciários. A seção seguinte traz os resultados. Finalmente, a seção 5 apresenta as considerações finais.

\section{Fundamentação Teórica e Evidências Empíricas}

\subsection{Aspectos Econômicos e Atuariais}

O marco teórico para estudar a desaposentação vem da literatura econômico-atuarial. O ponto central é, em primeiro lugar, o momento de início do recebimento da aposentadoria. Em segundo lugar, qual o impacto de uma alteração neste momento. Com esta finalidade, dois conceitos são fundamentais. O primeiro é a justiça atuarial (Actuarial Fairness), apresentado nos trabalhos de Queisser e Whitehouse (2006, p. 7-8) e Börsch-Supan (2006, p. 50). De acordo com esses autores, um sistema previdenciário pode ser classificado como atuarialmente justo se os valores presentes esperados das contribuições efetuadas e dos benefícios recebidos pelos segurados forem iguais. O segundo conceito é a neutralidade atuarial (Actuarial Neutrality). Neste caso, o conceito está ligado aos ganhos (em termos dos benefícios) e custos (em termos das contribuições) marginais associados a um desvio em relação a uma dada decisão de aposentadoria. Ou seja, uma postergação ou um adiantamento desta data. Em outras palavras, vale a neutralidade atuarial se os benefícios marginais líquidos (diferença entre benefícios e contribuições) não se alteram devido a uma alteração na data de aposentadoria. Com base em Hassler e Lindbeck (1996), pode-se argumentar ainda que neutralidade atuarial de um sistema previdenciário está relacionada à decisão ótima da oferta de trabalho do segurado.

A literatura que trata de neutralidade e justiça atuariais tem poucas contribuições. Entre os trabalhos teóricos podem ser citados Breyer e Kifmann (2002), que ressaltam a importância de não linearidades, brackets e mecanismos de ajustamento. Tais resultados são corroborados por Fisher e Keuschinigg (2010). Dentre os trabalhos empíricos podem ser elencados Reznik, Weaver e Biggs (2009), Forteza 
e Ourens (2012) e Shoven e Slavov (2012a e 2012b). De forma genérica, pode-se apontar que os resultados da literatura são bastante inconclusivos. Até onde se tem conhecimento, não há trabalhos nacionais que abordem este tema. Desta forma, pretende-se que a contribuição original deste trabalho seja a abordagem da desaposentação, fundamentada na literatura econômico-atuarial.

\subsection{Aspectos Jurídicos}

Pode-se afirmar que não há consenso claro sobre a legalidade ou não da desaposentação. É possível interpretar que o primeiro marco legal a tratar do assunto, ainda que de forma indireta, foi o Regulamento da Previdência Social (Decreto 3048/1999), que em seu artigo XXII, $\S 2$, afirma que "As aposentadorias por idade, tempo de contribuição e especial concedidas pela previdência social, na forma deste Regulamento, são irreversíveis e irrenunciáveis." Posteriormente, esta determinação foi ratificada por meio do Decreto 3265/1999, cujo artigo 181-B tem a mesma redação. A única exceção possível, ainda assim de forma indireta, foi incorporada nos termos do Decreto 6208/2007, que dá nova redação ao artigo 181-B do Decreto 3048:

Parágrafo único. O segurado pode desistir do seu pedido de aposentadoria desde que manifeste esta intenção e requeira o arquivamento definitivo do pedido antes da ocorrência do primeiro de um dos seguintes atos:

I - recebimento do primeiro pagamento do benefício; ou

II - saque do respectivo Fundo de Garantia do Tempo de Serviço ou do Programa de Integração Social.

Talvez a defesa jurídica favorável à desaposentação esteja amparada no próprio texto constitucional. O caput do artigo 195 menciona que "A seguridade social será financiada por toda a sociedade, de forma direta e indireta, nos termos da lei, mediante recursos provenientes dos orçamentos da União, dos Estados, do Distrito Federal e dos Municípios, e das seguintes contribuições sociais:" Dentre estas contribuições sociais inclui-se a contribuição previdenciária sobre o rendimento dos trabalhadores. 
Desta maneira, um trabalhador aposentado que se mantém no mercado de trabalho, continua efetuando contribuições à previdência como qualquer outro segurado. Por este argumento estaria enquadrado para pleitear uma nova aposentadoria no futuro. Adicionalmente, como o artigo citado menciona "toda a sociedade", seu critério de enquadramento é reafirmado, tendo em vista que já atendeu a condição de elegibilidade anteriormente.

Em uma das poucas referências jurídicas sobre o tema, Ibrahim (2011) afirma que, apesar de não possuir previsão legal expressa, a desaposentação poderia existir em qualquer regime previdenciário, desde que houvesse algum tipo de vantagem econômica para o segurado. Seu argumento sustenta-se no fato de que o expediente da desaposentação, em vez de violar direitos, apenas os amplia. $\mathrm{O}$ autor também é claro em fazer a distinção do correto termo a ser utilizado: aposentação é o "ato capaz de produzir mudança do status previdenciário do segurado, de ativo para inativo". Já aposentadoria é a "nova condição jurídica assumida pela pessoa". Portanto, desaposentação é a terminologia a ser utilizada.

Alguns projetos de lei na Câmara dos Deputados e no Senado da República sobre esta matéria, que permitiriam a existência da desaposentação, foram submetidos para apreciação nas duas casas. $\mathrm{Na}$ Câmara, propostas de regulação do direito de renúncia à aposentadoria por tempo de contribuição e especial, sem prejuízo para a contagem do tempo de contribuição tramitaram entre 2007 e 2010, notadamente nos projetos de lei 2682/2007, 3884/2008, 4264/2008 e 7092/2010. O único não rejeitado pela casa foi o PL 3884/2010. No momento em que este trabalho era redigido este projeto se encontrava sujeito à apreciação da Comissão de Finanças e Tributação. ${ }^{3}$ Vale ressaltar que o texto do PL 3884/2010, além de permitir a renúncia e o recálculo do benefício, é explícito quanto a não obrigatoriedade do aposentado a devolver ao INSS os valores recebidos quando da primeira aposentadoria. Já no Senado, um projeto com objetivo similar foi proposto: PLS 91/2010, texto que, até a elaboração deste trabalho, ${ }^{4}$ encontra-se sujeito à apreciação da Comissão de Agricultura e Reforma Agrária.

3 O andamento deste PL pode ser verificado em: www.camara.gov.br/proposicoesWeb/fichadetramitacao?idProposicao $=407274$.

4 A última verificação do PLS 91/2010 por parte dos autores, foi feita no dia 18/07/2013. O andamento deste PLS pode ser verificado em www.senado.gov.br/atividade/materia/detalhes. asp?p_cod_mate $=96319$. 


\subsection{Algumas Evidências Empíricas}

Com base nos argumentos apresentados, cabe perguntar sobre a importância que a desaposentação pode vir a ter. O Gráfico 1 apresenta algumas evidências de que há um expressivo contingente de pessoas nas idades mais avançadas que podem vir a pleitear a desaposentação. Neste gráfico os indivíduos são classificados de acordo com três características não excludentes: ${ }^{5}$

- Fazer parte ou não da PEA;

- Recebimento de aposentadoria

- Recebimento de pensão

É importante lembrar que de acordo com a legislação brasileira, uma pessoa não precisa deixar o mercado de trabalho ao começar a receber o benefício previdenciário. Da mesma forma, uma pessoa pode ser simultaneamente aposentada e pensionista e ainda assim continuar trabalhando.

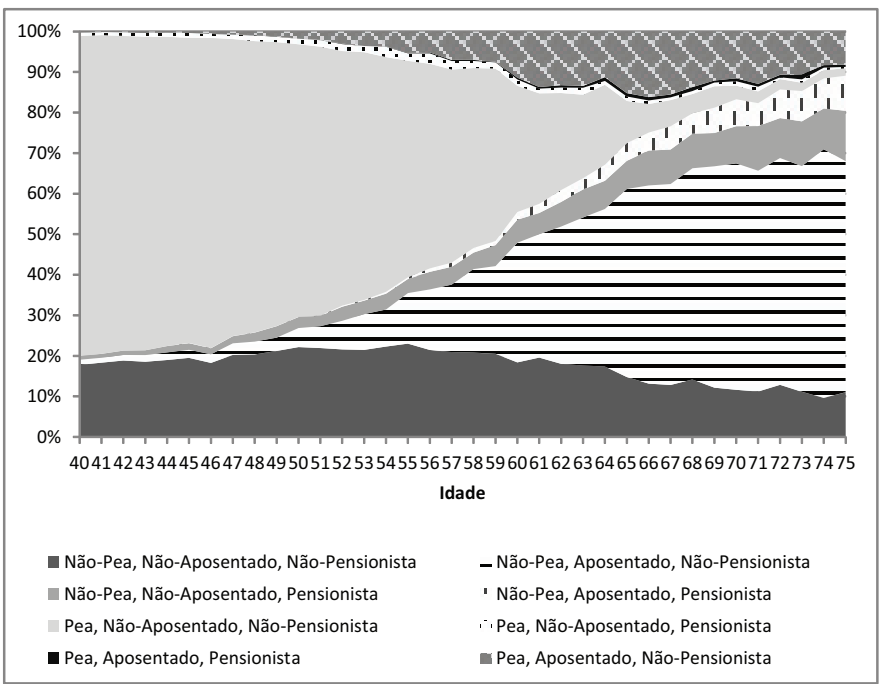

Gráfico 1 - Distribuição dos indivíduos conforme a inserção na PEA e condição de aposentado e/ou pensionista

Fonte: Microdados da PNAD 2011. Tabulações próprias

5 Estão excluídos os funcionários públicos estatutários, militares, trabalhadores na produção para o próprio consumo, trabalhadores na construção para o próprio uso e trabalhadores não remunerados. 
Para os propósitos deste trabalho, os indivíduos com as características mais relevantes são aqueles das duas faixas superiores: que fazem parte da PEA, recebem aposentadoria e recebem pensão e, principalmente, que fazem parte da PEA e recebem aposentadoria, mas não recebem pensão. Para as faixas etárias apresentadas no gráfico, estão incluídos nestas faixas, respectivamente, 141.259 e 3.136 .061 pessoas. A soma de ambos os valores perfaz o universo de possíveis pleiteantes da desaposentação junto ao INSS ${ }^{6}$. Note-se que por volta dos 65 anos, estes indivíduos representam quase 15\% do total da população apresentada.

\section{O Modelo}

Nessa seção é apresentado o modelo empregado na parte empírica. Enfatiza-se aqui que o trabalho concentra sua atenção sobre o benefício de Aposentadoria por Tempo de Contribuição (ATC), de acordo com as regras do Regime Geral de Previdência Social (RGPS) do Instituto Nacional do Seguro Social (INSS) para os assalariados urbanos do setor privado formal. A primeira parte trata das contribuições e a segunda parte, dos benefícios.

\subsection{Contribuições}

O RGPS é gerido, grosso modo, de acordo com um regime de repartição. Isto significa que os benefícios são financiados pelas contribuições dos segurados, sem que haja a formação de um fundo de reserva. As contribuições dos assalariados urbanos são feitas de forma não igualitária entre empregadores e empregados. Para os primeiros, a alíquota é de $20 \%$ da remuneração do empregado, sem limite superior. ${ }^{7}$ Para os empregados a alíquota varia de acordo com a renda bruta do trabalhador, havendo um limite máximo de inci-

${ }^{6}$ Pode haver uma pequena sobrestimação neste número, tendo em vista que os microdados da PNAD não permitem identificar a origem do benefício previdenciário. Desta forma os valores apresentados incluem o grupo de aposentados e pensionistas dos Regimes Próprios de Previdência Social (RPPS), que obviamente não poderão obter a desaposentação junto ao INSS.

7 Uma exceção são os empregados do setor financeiro e segurador, para os quais a alíquota é de $22,5 \%$. 
dência, conforme apresentado na Tabela 1. Nos termos do MPS, o salário-de-contribuição corresponde à renda do trabalhador, até o limite superior. ${ }^{8}$

Tabela 1 - Tabela de Contribuição (a partir de $1^{\circ}$ de janeiro de 2013)

\begin{tabular}{cc}
\hline Salário de contribuição $(\mathrm{R} \$)$ & Alíquota de Contribuição (\%) \\
\hline até $1.247,70$ & 8 \\
de $1.247,71$ a $2.079,50$ & 9 \\
de $2.079,51$ até $4.159,00$ & 11 \\
\hline
\end{tabular}

Fonte: Ministério da Previdência Social (MPS).

O primeiro passo para calcular as contribuições é prever a evolução da renda de um segurado com renda inicial $W_{0}$. Supóe-se uma taxa de crescimento constante $r$ ao longo de seu período laboral. Portanto, seu salário mensal $W_{t}$ no instante $t$ pode ser expresso em função de $W_{0}$ e do número de períodos $t$, conforme apresentado na Equação 1 .

$$
W_{t}=W_{0} \times(1+r)^{t}
$$

Desta maneira, como mostra a Equação 2, a cada instante do tempo $t$ o valor das contribuições previdenciárias é dado pela multiplicação do salário pela alíquota de contribuição $a_{t}$ (soma das alíquotas do empregador e do empregado, esta última dada em função da faixa de renda, de acordo com a Tabela 1).

$$
V C_{t}=W_{0} \times(1+r)^{t} \times a_{t}
$$

O valor presente das contribuições é dado pela Equação 3, na qual Im é a idade de entrada no mercado de trabalho, Ia é a idade de aposentadoria e $T x$ é a taxa real de juros. Ressalta-se que em cada ano há 13 contribuições, devido ao $13^{\circ}$ salário.

$$
V P C=\sum_{n=I m}^{I a} \frac{V C_{n}}{(1+T x)^{n}}
$$

8 Por exemplo, se a renda do trabalhador é de $\mathrm{R} \$ 5.000,00$, a alíquota de contribuição do empregador incide sobre este total, enquanto a contribuição do trabalhador está limitada $11 \%$ incidentes sobre $\mathrm{R} \$ 4.159,00$. 


\subsection{Beneficios}

A condição de elegibilidade para a Aposentadoria por Tempo de Contribuição do RGPS são 35 anos de contribuição para homens e 30 anos para mulheres, não havendo requisito de idade mínima. Os benefícios são pagos mensalmente de forma vitalícia. Sua cessação ocorre quando do falecimento do segurado, a não ser que se tenha dependentes vivos. Nesse caso, o benefício converte-se em pensão por morte. Desde 1999, o valor do Salário-de-Benefício (SB) é calculado por meio do produto da média aritmética $M$ dos $80 \%$ maiores salários de contribuição pelo Fator Previdenciário $(f)$, conforme apresentado na Equação 4.

$$
S B=M \times f
$$

O fator previdenciário $f$, apresentado na Equação 5, é uma formulação ad hoc, apresentada no Decreto 3265/1999. Nesta expressão, Tc e Id são, respectivamente, o tempo de contribuição e a idade quando do pedido de aposentadoria, $a$ é alíquota de contribuição (de valor igual a 0,31 para todos os segurados) e Es é a expectativa de sobrevida para ambos os sexos, calculada anualmente pelo IBGE.

$$
f=\frac{T c \times a}{E s} \times\left[1+\frac{(I d+T c \times a)}{100}\right]
$$

Combinando as Equações 4 e 5, tem-se a expressão para o cálculo do valor do Salário-de-Benefício $S B$ dada pela expressão 6. O valor do Salário-de-Benefício está sujeito ao mesmo limite do Salário-deContribuição (R $\$ 4.159,00)$, conforme apresentado na Tabela 1.

$$
S B=M \times\left\{\frac{T c \times a}{E s} \times\left[1+\frac{(I d+T c \times a)}{100}\right]\right\}
$$

O fator previdenciário tem por objetivo aumentar o grau de justiça atuarial (nos termos de Queisser e Whitehouse, 2006) das aposentadorias concedidas pelo INSS. ${ }^{9}$ Quanto mais o segurado postergar

9 O uso do Fator Previdenciário é obrigatório para as aposentadorias por tempo de contribuição e opcional para as aposentadorias por idade. 
sua aposentadoria, mais elevado será o fator e, portanto, o valor do benefício. De forma oposta, aposentadorias mais precoces (atendendo os requisitos mínimos) implicam em benefícios de menor valor.

Quatro pontos merecem destaque na formulação do fator previdenciário. O primeiro é a diferenciação por gênero. No caso das mulheres, há um acréscimo de cinco anos no tempo de contribuição, o que contribui para aumentar o valor de seu benefício. O segundo é a influência da expectativa de sobrevida: por força da lei, os valores de $E s$ modificam-se de forma não obrigatoriamente linear a cada ano. Estes valores, por força de ato legal, são divulgados anualmente pelo IBGE. Desta maneira, determinadas coortes podem ser mais afetadas por aumentos na expectativa de sobrevida (que tendem a reduzir seu benefício) do que outros. Em terceiro lugar, deve ser notado que não há diferenciação por gênero no termo Es: são empregados os valores da Tábua Ambos os Sexos do IBGE. Uma vez mais as mulheres são beneficiadas, pois a expectativa de sobrevida média adotada nos cálculos é inferior à sua expectativa real. Finalmente, é importante lembrar que o fator previdenciário só foi adotado quando o governo não conseguiu viabilizar a adoção de uma idade mínima para a ATC. Desta forma, foi implantada na verdade uma nova regra de cálculo e não uma condição de elegibilidade mais rígida. E, implicitamente, deixou-se margem para que aposentados em idades baixas explorassem posteriormente a possibilidade de obter a desaposentação.

De forma análoga ao apresentado para as contribuições, o valor presente dos benefícios é dado pela Equação 7. O Salário-de-Benefício $S B$ é recebido do momento imediatamente posterior ao pedido da aposentadoria $(I a+1)$, até a expectativa de vida $E s$.

$$
V P B=\sum_{n=I a+1}^{E s} \frac{S B_{n}}{(1+T x)^{n^{\prime}}}
$$

Combinando as Equações 6 e 7, tem-se a Equação 8, que expressa o valor presente dos benefícios em função das demais variáveis.

$$
V P B=\sum_{j=I a}^{E s} \frac{M \times\left\{\frac{T c \times a}{E s} \times\left[1+\frac{(I d+T c \times a)}{100}\right]\right\}}{(1+T x)^{j}}
$$




\subsection{Premissas e Hipóteses}

Uma vez apresentado o modelo, são explicitadas as premissas empregadas para os cálculos da desaposentação. O objeto de análise deste trabalho são os empregados do setor formal urbano, que contribuem com o Regime Geral de Previdência Social. Supõe-se que estes segurados iniciaram sua vida profissional e trabalharão por toda sua vida ativa no setor privado formal. Desta forma sua densidade de contribuições é de $100 \%$. É feita a suposição inicial de que estes indivíduos obedecem estritamente às regras e condições mínimas do RGPS. Ou seja, aposentam-se tão logo preencham as condições de elegibilidade. Dadas as regras atuais, os homens podem solicitar a ATC com 35 anos e as mulheres com 30 anos de contribuição. Desta forma, sua variável de escolha é o momento de solicitação da desaposentação. Admite-se, por hipótese, que homens e mulheres entram no mercado com 20 anos de idade. O período de recebimento do benefício é determinado pela expectativa de vida média desagregada por gênero, divulgada anualmente pelo IBGE. No momento em que este artigo era finalizado, a expectativa era de 70,60 anos para os homens e de 77,70 anos para as mulheres.

Todos os fluxos de contribuições e de benefícios são mensais e os valores empregados nos cálculos são expressos em termos reais. Também será feita a hipótese simplificadora que a renda cresce $2 \%$ ao ano para todos os trabalhadores. A taxa de desconto empregada nos cálculos é de 3\% ao ano. Para uma análise da sensibilidade dos resultados para valores distintos destas taxas, ver, por exemplo, Giambiagi e Afonso (2009). Finalmente, cabe apontar que este trabalho não aborda as pensões por morte. Apesar de sua relevância, analisar este tema significaria fazer uma série de hipóteses e análises com relação à composição dos grupos familiares, o que foge totalmente ao escopo pretendido.

\subsection{Representação Esquemática dos Fluxos de Contribuições e Bene- ficios}

Para ilustrar o problema, apresenta-se o Gráfico 2, no qual são representados os fluxos mensais de contribuições (positivos) e de benefícios previdenciários (negativos) de um indivíduo ao longo de sua vida. 
Considera-se que este segurado hipotético do gênero masculino inicia sua vida ativa com uma renda mensal de um salário mínimo (SM) (R \$ 678,00), que cresce monotonicamente. Esta pessoa, tendo iniciado sua vida ativa aos 20 anos, aposenta-se por tempo de contribuição aos 55 anos e deixa o mercado de trabalho, de acordo com as regras vigentes. Suas contribuições durante esse período estão representadas área 1 . O segurado passa a receber imediatamente sua aposentadoria por tempo de contribuição de modo vitalício. $\mathrm{O}$ fluxo de benefícios da ATC está representado pelas áreas 3 e 4. Não havendo dependentes, o pagamento do benefício ocorrerá até os 70,6 anos, conforme a expectativa de sobrevida hoje prevalecente.

Considere-se agora a possibilidade da desaposentação. O segurado se aposenta por tempo de contribuição e se torna beneficiário do RGPS. No entanto, de forma diferente das condições mencionadas no parágrafo anterior, continua no mercado de trabalho e mantém sua condição de contribuinte ao RGPS. Após alguns anos, o segurado solicita uma revisão do valor do seu benefício, de forma a incorporar no cálculo do benefício as contribuições efetuadas no seu período de trabalho adicional. Esta é a desaposentação.

No exemplo do Gráfico 2, o pedido de desaposentação é feito aos 60 anos, 5 anos após a aposentadoria original. As contribuições adicionais, correspondentes à permanência no mercado de trabalho, estão representadas na área 2. Esta continuidade da vida ativa implica crescimento do salário e do fator previdenciário. Desta maneira, o novo fluxo de benefícios corresponde às áreas 4 e 5 .

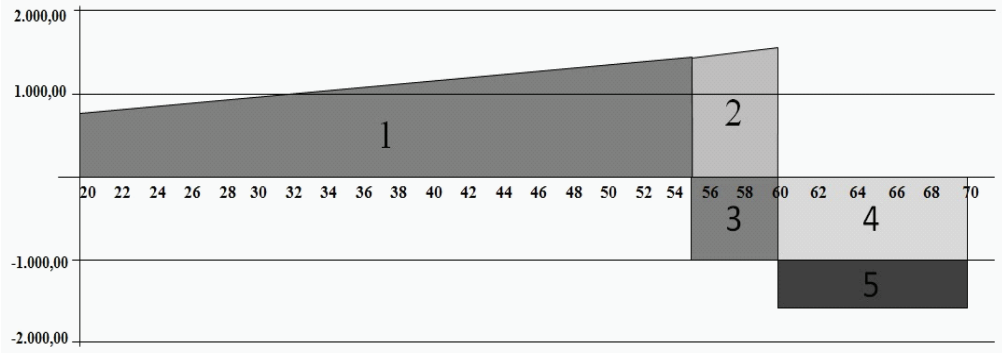

Gráfico 2 - Fluxos de rendas de um indivíduo hipotético (vida ativa e inativa) (Segurado do gênero masculino - Com ou sem desaposentação)

Fonte: Elaboração dos autores. 


\subsection{Indicadores Previdenciários}

Todos os resultados obtidos serão analisados com base em quatro indicadores usuais na literatura previdenciária. São eles: Taxa de Reposição (TR), Alíquota Efetiva (AE), Alíquota Necessária (AN) e Taxa Interna de Retorno (TIR). Dois trabalhos quem empregam alguns desses indicadores são Schröder (2012) e Forteza e Ouréns (2009).

A forma de cálculo da Taxa de Reposição TR é apresentada na Equação 9, na qual $V u C$ é a remuneração no último período laboral e $V p B$ é o valor do primeiro benefício previdenciário do indivíduo.

$$
T R=\frac{V p B}{V u R}
$$

A Alíquota Efetiva $(A E)$, apresentada na Equação 10, expressa a relação entre os valores presentes das contribuições de fato realizadas $(V P C)$ e da renda (VPR) que o segurado pagou durante o período contributivo.

$$
A E=\frac{V P C}{V P R}
$$

A Alíquota Necessária $(A N)$ indica qual deveria ser a alíquota de contribuição que assegurasse o equilíbrio entre os valores presentes de contribuições e benefícios $(V P B)$. Sua fórmula está explicitada na Equação 11.

$$
A N=\frac{V P B}{V P R}
$$

Conforme apresentado na Equação 12, a Taxa Interna de Retorno (TIR) iguala os fluxos de contribuições e benefícios do segurado durante sua vida. Nesta expressão o termo $F_{t}$ representa a contribuição e/ou benefício (com sinais trocados) no instante de tempo $t$.

$$
0=\sum_{t=0}^{E s} \frac{F_{t}}{(1+T I R)^{t}}
$$


Os trabalhadores que potencialmente solicitarão a desaposentação (isto é, que se aposentam, mas não deixam o mercado de trabalho formal) por alguns períodos são contribuintes e beneficiários. Neste caso o termo $F_{t}$ representa a diferença entre os dois fluxos monetários. No Gráfico 1, esta situação é representada pelas áreas 2 e 3.

\section{Resultados}

Nesta seção são apresentados os resultados do trabalho, efetuando os cálculos dos indicadores previdenciários apresentados na seção 3. Inicialmente reportam-se os valores obtidos no Cenário Base, situação previdenciária mais usual, em que não há desaposentação. Posteriormente é feita a análise de sensibilidade do modelo, com a mudança em algumas variáveis de escolha, particularmente o momento de entrada em desaposentação. Por fim, serão apresentados os resultados supondo que haja a devolução dos benefícios recebidos durante o período anterior ao pedido de desaposentação.

\subsection{Cenário Base - Modelo sem Desaposentação}

O Cenário Base, cujos resultados são reportados na Tabela 2, servirá como padrão de comparação para os resultados obtidos para as alternativas de desaposentação analisadas. Inicialmente, serão considerados um trabalhador e uma trabalhadora que ingressaram no setor formal aos 20 anos de idade e obtiveram a ATC após 35 anos (homem) e 30 anos (mulher). A expectativa de vida ao nascer é aquela divulgada pelo IBGE em 2011 (70,6 anos para homens e 77,7 anos para mulheres). Todos os valores monetários são atualizados pelos índices reais de crescimento (crescimento da renda de $2 \%$ ao ano, taxa real de juros de 3\% ao ano). Por fim, o salário mínimo inicial é aquele vigente em 2013 ( $\mathrm{R} \$$ 678,00). Os indicadores são calculados para oito combinações de parâmetros: sexo (masculino e feminino) e valores de renda inicial (1, 2, 3 e 5 SM). 
Tabela 2 - Indicadores previdenciários - Cenário base

\begin{tabular}{|c|c|c|c|c|c|c|}
\hline \multirow{9}{*}{ 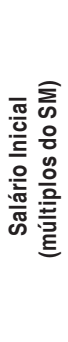 } & & & TIR (\% a.a.) & TR & $A E(\%)$ & AN (\%) \\
\hline & \multirow{2}{*}{1} & H & 0,79 & 0,56 & 28,10 & 16,30 \\
\hline & & M & 3,28 & 0,56 & 28,00 & 30,01 \\
\hline & \multirow{2}{*}{2} & $\mathrm{H}$ & 0,54 & 0,56 & 29,66 & 16,30 \\
\hline & & M & 2,50 & 0,48 & 29,47 & 25,63 \\
\hline & \multirow{2}{*}{3} & H & 0,39 & 0,56 & 30,87 & 16,30 \\
\hline & & M & 2,33 & 0,48 & 30,85 & 25,63 \\
\hline & \multirow{2}{*}{5} & $\mathrm{H}$ & $-0,29$ & 0,45 & 29,58 & 13,09 \\
\hline & & M & 1,86 & 0,41 & 29,92 & 21,81 \\
\hline
\end{tabular}

Fonte: Cálculos dos autores.

Os resultados obtidos são comparáveis àqueles apresentados na literatura nacional (Giambiagi e Afonso, 2009; Caetano, 2006; e Afonso e Fernandes, 2005) e internacional (Van Duijn et al. (2013) para o caso holandês, e Gustman et al. (2012) para o caso dos EUA), apresentando de forma geral evidências da existência de subsídios implícitos intrageracionais para as mulheres. Isto pode ser notado pelos valores mais elevados para a $T I R, T R$ e $A N$ para o grupo feminino. No caso da Alíquota Necessária, os valores das mulheres são sempre significativamente inferiores à alíquota de contribuição vigente $(28$ a $31 \%$ ). Dois pontos devem ser ressaltados. O primeiro é o decréscimo monotônico nos valores da TIR para faixas de renda mais elevada, o que é uma evidência da existência de princípios distributivos intrageracionais, dos grupos mais ricos para os mais pobres. O segundo ponto é a grande diferença, tanto para a $T I R$, quanto para a $A N$ entre homens. Aparentemente, este resultado é devido ao emprego nos cálculos, de tábuas de mortalidade distinta para os dois gêneros, diferentemente do que o INSS faz no cálculo do fator previdenciário, em que é empregada a tábua de ambos os sexos do IBGE.

\subsection{Resultados com Desaposentação}

Nesta seção são calculados os indicadores previdenciários da seção 3.5, na existência da desaposentação. Inicialmente supõe-se que ao se desaposentar há dois fluxos: o primeiro é o recebimento do benefício recalculado, de acordo com os novos parâmetros. O segundo corresponde à devolução, de forma parcelada, ao INSS, dos benefícios recebidos durante o período de aposentadoria original (área 3 do Gráfico 1). O valor da parcela mensal devolvida será a diferença 
entre o valor do benefício na aposentadoria e na desaposentação. Será mensurado o tempo, em anos, necessário para quitar a última parcela da dívida (denotado por tempo para retorno).

Os resultados da desaposentação estão divididos em duas tabelas. $\mathrm{Na}$ Tabela 3 apresentam-se os valores para indivíduos cuja renda inicial era de 1 ou 2 SM e na Tabela 4, os casos em que a renda inicial é de 3 ou 5 SM. Em ambos os casos, nas linhas das tabelas são apresentadas diversos tempos de desaposentação (em anos), ou seja, o tempo que o segurado leva para pleitear uma revisão do valor do seu benefício.

Tabela 3 - Indicadores previdenciários com desaposentação (Renda inicial: 1 e $2 \mathrm{SM}$ )

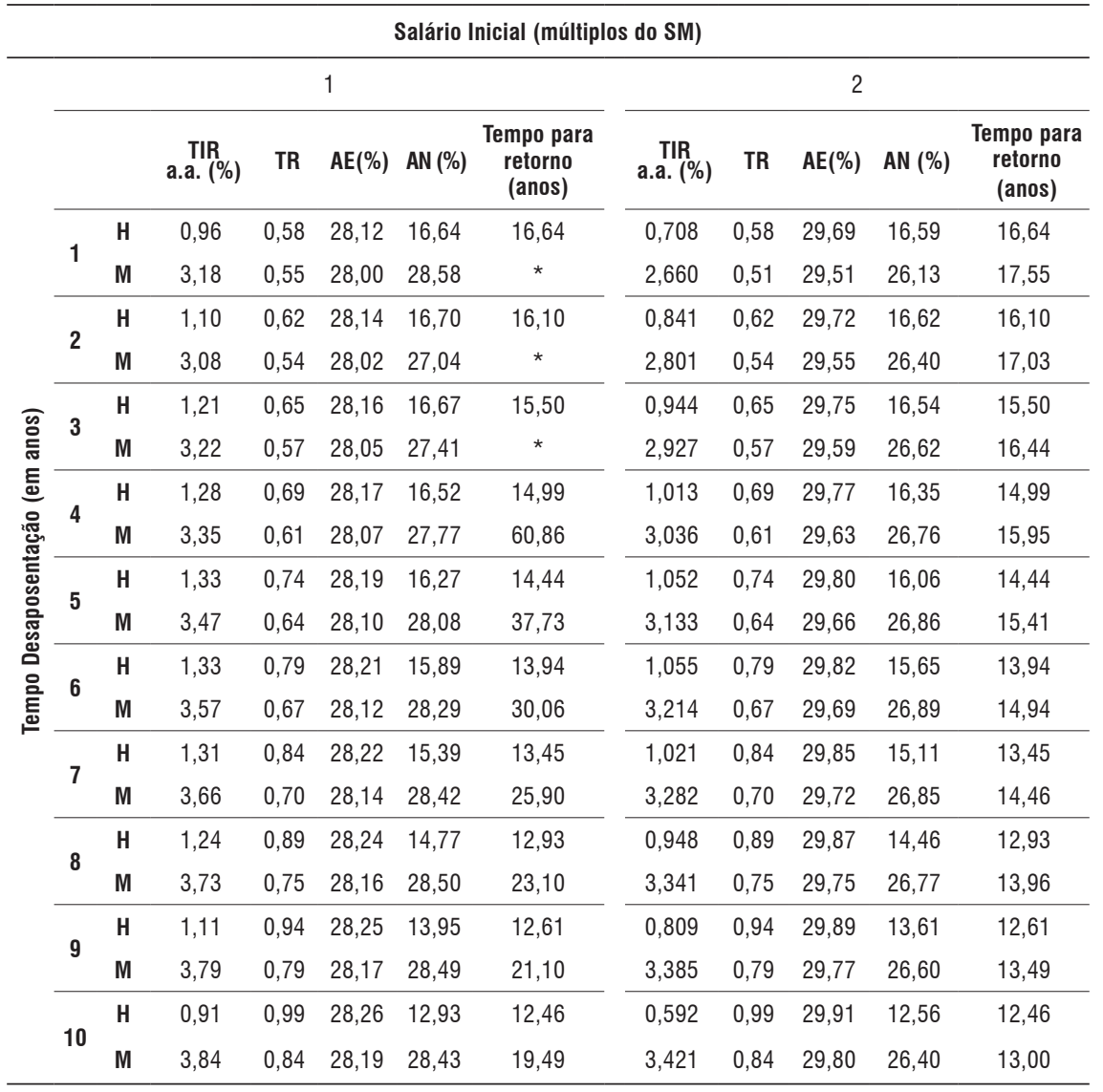

* Não há tempo para pagamento do benefício ganho de aposentadoria.

Fonte: Cálculo dos autores. 
Tabela 4 - Indicadores previdenciários com desaposentação (Renda inicial: 3 e $5 \mathrm{SM})$

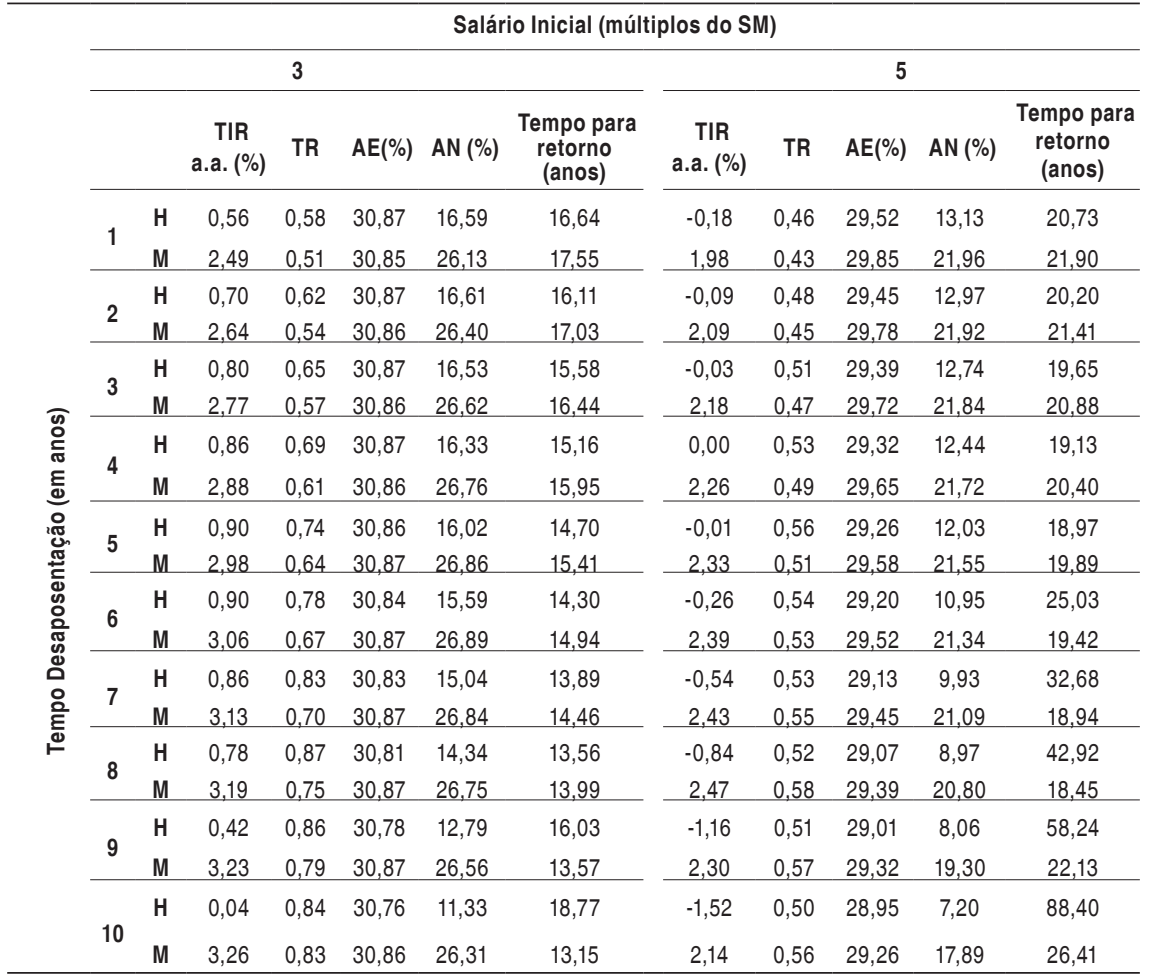

* Não há tempo para pagamento do benefício ganho de aposentadoria.

Fonte: Cálculo dos autores.

Pode-se observar que a TR dos homens é sempre maior que das mulheres. Dois motivos explicam este fato. O primeiro é devido ao fato de os homens trabalharem cinco anos a mais para se aposentar, de forma que seu fator previdenciário é mais elevado. O segundo deve-se a uma hipótese do modelo. Como os salários crescem monotonicamente, o salário de contribuição dos homens no final do período laboral é mais alto. Desta forma, a média de seus salários é mais elevada, ocorrendo o mesmo com seu salário de benefício. A única exceção ocorreria se o salário-de-contribuição ou o saláriode-benefício atingissem o teto legal.

Os valores da TIR e da $\mathrm{AN}$ são sempre mais elevados e apresentam crescimento mais acentuado para as mulheres, o que se explica por seu menor tempo de contribuição e maior expectativa de sobrevida. 
Os resultados das Tabelas 3 e 4 fornecem evidências da existência de um resultado bastante interessante: há um momento ótimo de solicitar a desaposentação. Ou seja, conforme mencionado na introdução: se a desaposentação for solicitada de forma muito prematura, o ganho é pequeno. Se houver uma demora muito grande, o período de recebimento é muito reduzido. Logo, há uma escolha que maximiza a multiplicação do tempo de recebimento pelo valor do benefício adicional.

O Gráfico 3 apresenta a TR em função do tempo de desaposentação. Pode-se observar que a TR é sempre maior para os homens, à exceção do piso de $1 \mathrm{SM}$, em que há igualdade entre gêneros. Também deve ser ressaltado que não há monotonicidade nos valores da TR. Para os homens há redução nos valores nas faixas superiores a 3 $\mathrm{SM}$, enquanto para as mulheres este fenômeno ocorre somente a partir de 4 SM. A explicação desta diferença deve buscada no fator previdenciário: como o fator é maior para os homens, eles atingem mais rapidamente o teto do salário de benefício e isso faz com que a queda aconteça para faixas menores de renda e para períodos de desaposentação menores.

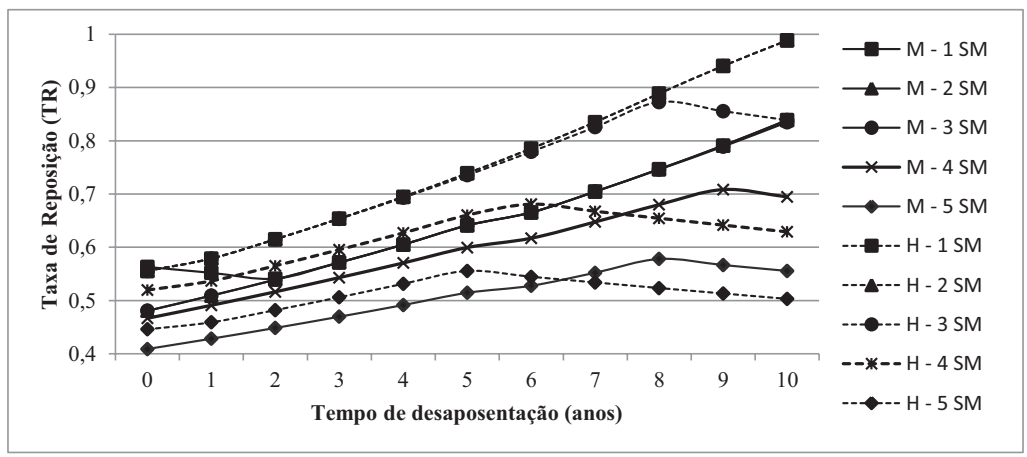

Gráfico 3 - Taxa de Reposição em função do tempo de desaposentação Fonte: Elaboração própria.

O Gráfico 4 apresenta a TIR. Para os homens, os pontos de máximo ocorrem, no mínimo, em 4 anos e 10 meses entre a aposentadoria e o pedido de recálculo do benefício, para todas as faixas de salário. Para a faixa de $5 \mathrm{SM}$, há apenas taxas negativas, à exceção do ponto de máximo, que ocorre após 4 anos e 10 meses após o pedido de 
desaposentação. Já o comportamento da TIR para o gênero feminino não é tão claro quanto ao período ótimo para pedir a desaposentação. Por exemplo, para a renda inicial de 1 SM o ponto de mínimo ocorre 2 anos após a aposentadoria e o de máximo após 12 anos e 10 meses. Já para a faixa de $5 \mathrm{SM}$, o ponto de máximo ocorre aos 8 anos.

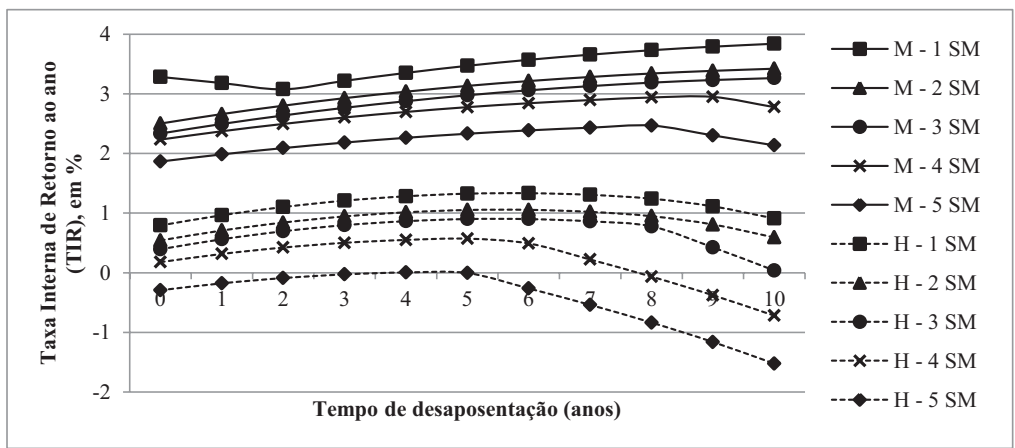

Gráfico 4 - Taxa Interna de Retorno (TIR) em função do tempo de desaposentação

Fonte: Elaboração própria.

A TIR tem um comportamento crescente até atingir o máximo com 5 anos e 10 meses após a aposentadoria para os homens, e com 7 anos 10 meses ou mais para as mulheres e depois sofrendo uma diminuição. Assim, pelo fato de haver um ponto de máximo para a $T I R$, para ambos os gêneros e todas as faixas de renda, evidencia-se que pode haver um momento ótimo para a desaposentação, conforme o resumo feito na Tabela 4 . O prazo ideal para a desaposentação é de no mínimo 4 e 10 meses anos após a aposentadoria para os homens de todas as faixas de renda. Para as mulheres, os tempos ótimos de desaposentação são sempre mais elevados.

Tabela 5 - Tempo ótimo para desaposentação em anos (TIR máxima)

\begin{tabular}{cccccc}
\hline \multicolumn{6}{c}{ Salário Inicial (múltiplos do SM) } \\
\hline & $\mathbf{1}$ & $\mathbf{2}$ & $\mathbf{3}$ & $\mathbf{4}$ & $\mathbf{5}$ \\
\hline H & 5,83 & 5,83 & 5,83 & 4,83 & 4,83 \\
M & 12,83 & 12,83 & 10,83 & 8,83 & 7,83 \\
\hline
\end{tabular}

Fonte: Elaboração própria. 
O Gráfico 5 apresenta a Alíquota Efetiva $(A E)$ em função do número de anos de desaposentação. Nota-se que em todos os níveis de salário inicial a $A E$ dos homens é maior do que a das mulheres. Para combinações de renda acima de $3 \mathrm{SM}$ mais de 5 anos de desaposentação, a alíquota efetiva das mulheres é maior que a dos homens. Parece ser possível afirmar que o comportamento crescente encontrado para salários iniciais inferiores a $2 \mathrm{SM}$ é explicado pela própria regra de contribuição, que estabelece alíquotas diferenciadas e crescentes para níveis de renda mais altos.

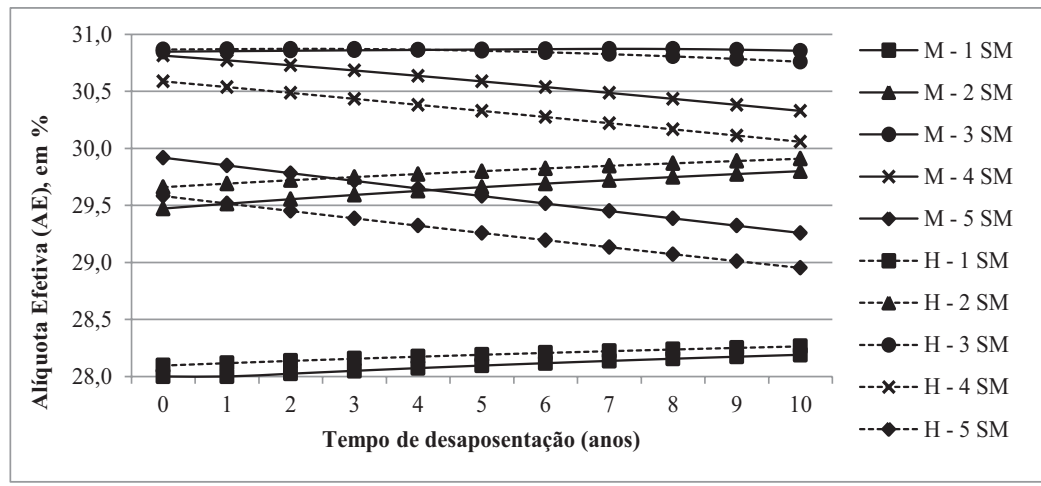

Gráfico 5 - Alíquota Efetiva (AE) em função do tempo de desaposentação Fonte: Elaboração própria.

O Gráfico 6 apresenta os valores da Alíquota Necessária $(A N)$. Este indicador é muito importante, pois expressa a alíquota previdenciária que deveria incidir sobre o salário dos indivíduos (inexistindo descontinuidades ou limites de contribuição) para que os fluxos de contribuições e benefícios fossem iguais para cada indivíduo. Este gráfico evidencia três pontos relevantes: (a) quanto mais os contribuintes postergam a aposentadoria (ou mesmo a desaposentação), mais baixa deveria ser a sua alíquota; (b) diferencial de gênero: os homens deveriam ter uma alíquota menor que as mulheres; (c). Diferencial de renda: quanto maior o salário inicial, menor deveria ser a alíquota cobrada. Os dois últimos pontos são mais uma evidência de características distributivas nas regras de ATC do RGPS, de homens para mulheres e dos indivíduos mais ricos para os mais pobres. 


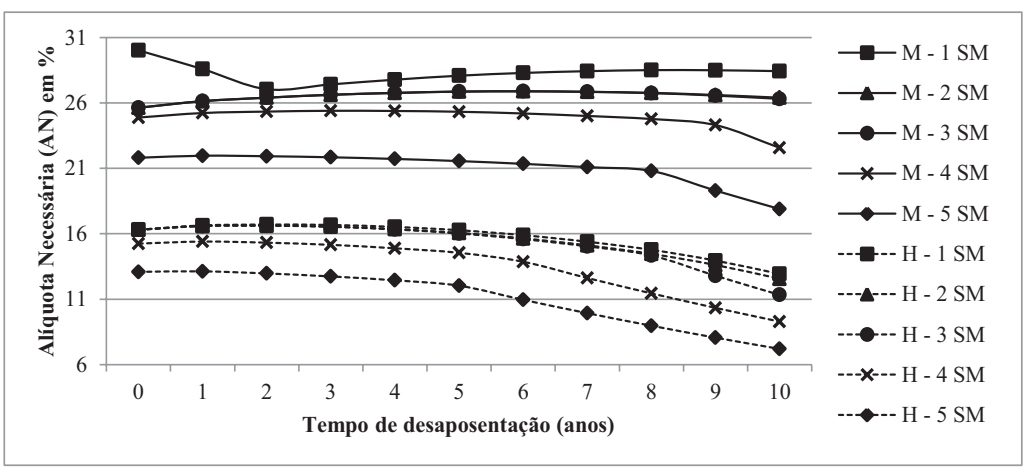

Gráfico 6 - Alíquota Necessária (AN) em função do tempo de desaposentação Fonte: Elaboração própria.

\subsection{Modelo com Desaposentação: Uma Extensão}

Considerando a hipótese de devolução do valor recebido de benefício durante a aposentadoria, o tempo para retorno, evidenciado pelo Gráfico 7, indica que este mecanismo pode criar uma barreira ao pedido de desaposentação. Isso ocorreria para ambos e sexos e as quatro faixas salariais iniciais devido ao fato de que o tempo necessário para quitação da dívida previdenciária coincide com o tempo de vida das pessoas. Na prática, o mecanismo de devolução do benefício faria com que o aumento de benefício fosse diferido no mínimo, 12 anos. Ou seja, a desaposentação só seria vantajosa para o segurado se ele viver, pelo menos, entre 13 e 22 anos após o pedido de desaposentação.

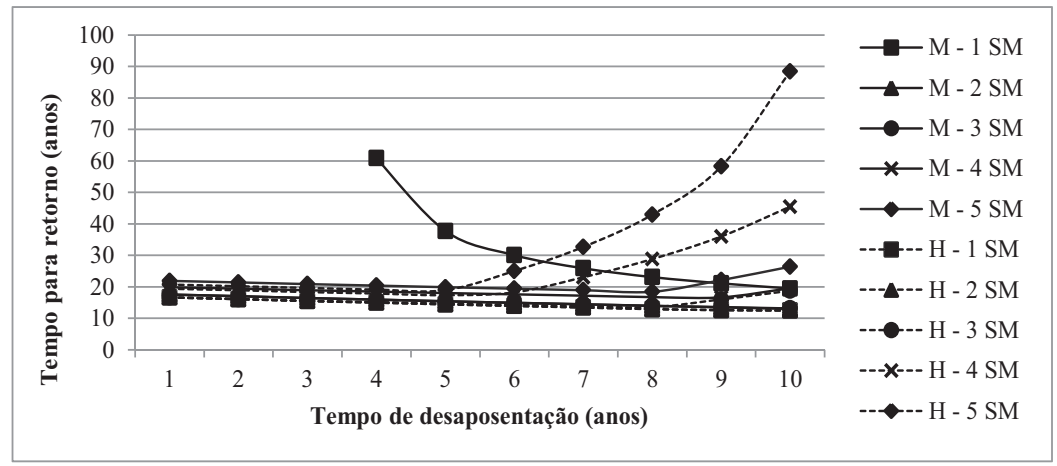

Gráfico 7 - Tempo para Retorno em função do tempo de desaposentação Fonte: Elaboração própria. 
Entretanto, há dois grupos que aparentam clara desvantagem neste aspecto, uma vez que precisariam viver por mais de 40 anos após o pedido de desaposentação para quitar a diferença do benefício recebido: mulheres com renda inicial de $1 \mathrm{SM}$ e homens com 4 e 5 SM. A primeira situação ocorre devido à reduzida diferença entre o salário de benefício de aposentadoria e o de desaposentação. Isso ocorre uma vez que o benefício atinge um valor próximo ao mínimo e, portanto, permanece aproximadamente constante para uma desaposentação de 3 anos. Ou seja, esta mulher segurada não terá aumento relevante de benefício e permanecerá próxima do piso. Já para o caso dos homens de maior renda inicial, mais alto deve ser o benefício. Além disso, quanto mais tarde o indivíduo pede o recálculo, mais próximo do teto legal ele está, e também sua expectativa de sobrevida é menor. Assim, maior é o tempo para retorno e, portanto, maior é a desvantagem da desaposentação.

\section{Considerações Finais}

Neste trabalho, foram analisados os impactos da desaposentação para a aposentadoria por tempo de contribuição, do ponto de vista da escolha individual ótima do segurado. Isso é evidenciado pela existência de um valor de TIR máximo no período de desaposentação. A TIR cresce até atingir o valor máximo 4 anos e 10 meses após a aposentadoria (homens) e 7 anos e 10 meses ou (mulheres), caindo a seguir.

Estes resultados evidenciam a existência de um momento ideal para pedir o recálculo do benefício previdenciário. Este prazo é de 4 anos e 10 meses após a aposentadoria para os homens das faixas superiores de renda e 5 anos e 10 meses para homens de renda mais baixas, pois eles obterão um retorno maior entre as contribuições e benefícios. No caso das mulheres, esse tempo diminui conforme aumenta a faixa salarial, pois uma pessoa com renda inicial igual a 5 SM terá seu retorno máximo após 7 anos e 10 meses. Por outro lado, se a renda inicial for $1 \mathrm{SM}$, o retorno mais elevado será alcançado aos 12 anos. Considerando o cenário de devolução do benefício de aposentadoria para manter a justiça atuarial e utilizando a mesma hipótese adotada, percebe-se que a desaposentação não se torna vantajosa para a maioria das faixas de salário e tempo de desaposentação, pois o 
aumento conseguido no recálculo do benefício seria totalmente consumido para o pagamento parcelado do benefício de aposentadoria. Como a expectativa de sobrevida dos homens é menor, todos os segurados do sexo masculino que tivessem que devolver o montante recebido na aposentadoria seriam favorecidos, pois em tese completariam a devolução somente após a sua morte.

Para as mulheres haveria algumas situações nas quais seria vantajoso pedir o recálculo do benefício, quando se considera o cenário em que é necessário devolver os benefícios recebidos. As mulheres com renda inicial de 2 e $3 \mathrm{SM}$ seriam favorecidas, para qualquer momento de solicitação da desaposentação até 15 anos. Para o salário inicial de $1 \mathrm{SM}$, nenhuma mulher teria aumento no valor de benefício de desaposentação de tal modo que conseguisse pagar todo o valor devido. O mesmo acontece para 4 SM e tempo de desaposentação maior que 10 anos e as que estão nas faixas $5 \mathrm{SM}$ e tempo de desaposentação maior que 9 anos. Verifica-se ainda que a existência da obrigatoriedade na devolução dos benefícios poderia significar uma barreira aos pedidos de recálculo de benefícios para a maioria dos segurados, já que o trade off entre o aumento do valor do benefício e a devolução do montante recebido anteriormente não lhes seria favorável.

É válido notar a existência de não monotonicidades em vários dos indicadores calculados, particularmente a TIR, conforme reportado, por exemplo, nas Tabelas 3, 4 e 5. Esta característica deve-se às não linearidades existentes na ATC, tanto em relação ao período contributivo, quanto em relação ao cálculo do benefício, particularmente pela existência do Fator Previdenciário. Estes resultados também mostram que indicadores contemporâneos, como a $T R$ por vezes não conseguem captar de forma adequada a complexidade dos regimes previdenciários de repartição, particularmente quanto aos aspectos distributivos. Daí a necessidade do cálculo de indicadores de caráter intertemporal, como a TIR e $A N$. O cálculo da TIR tem ainda outra vantagem, que é não imposição de uma taxa de desconto para um regime de repartição, ponto ainda pouco consensual na literatura, como reportam Comprix e Muller (2011) e Brown e Wilcox (2009).

Por fim, o cálculo da TIR traz implícito o conceito de justiça atuarial, tendo em vista que esta é a taxa que iguala os valores presentes dos fluxos de benefícios e contribuições. Característica similar apresenta a $A N$, que expressa a relação entre valores presentes dos 
benefícios e da renda. Desta maneira, valores mais elevados da TIR sinalizam retorno implícito do regime de repartição mais elevado. Como as taxas de retorno são diferentes (mais elevadas para mulheres e indivíduos de renda mais baixa) deve ser notado que a justiça atuarial não significa per se a existência de TIRs iguais para perfis individuais distintos. Analogamente, como em todas as situações apresentadas, os valores da TIR e da $A N$ apresentaram mudanças, isto significa que o benefício de ATC do RGPS não pode ser caracterizado como atuarialmente neutro. Ou seja, o atual conjunto de regras muito provavelmente oferece incentivos e desincentivos monetários à mudança da data da aposentadoria, uma vez cumpridos os requisitos legais mínimos.

\section{Referências}

AFONSO, L. E.; FERNANDES, R. Uma estimativa dos aspectos distributivos da previdência social no Brasil, Revista Brasileira de Economia, v. 59, n. 3, p. 295-334, 2005.

BRASIL. Constituição (1988). Constituição da República Federativa do Brasil. Brasília, DF: Senado, 1988.

BRASIL. Decreto 3.265, de 29 de novembro de 1999, Altera o Regulamento da Previdência Social, aprovado pelo Decreto n ${ }^{\circ} 3.048$, de 6 de maio de 1999, e dá outras providências. Diário Oficial [da] República Federativa do Brasil, Poder Executivo, Brasília, DF, 30 nov. 1999.

BRASIL. Decreto 3.048, de 06 de maio de 1999, Aprova o Regulamento da Previdência Social, e dá outras providências. Diário Oficial [da] República Federativa do Brasil, Poder Executivo, Brasília, DF, 07 mai. 1999.

. Decreto $n^{\circ} 6.208$ de 18 de setembro de 2007, Dá nova redação ao parágrafo único do art. 181-B do Regulamento da Previdência Social, aprovado pelo Decreto no 3.048, de 6 de maio de 1999. Diário Oficial da República Federativa do Brasil, Brasília, DF, 19 de setembro de 2007.

BREYER, F.; KIFMANN, M. Incentives to retire later - a solution to the social security crisis? Journal of Pension Economics and Finance, v. 1, n. 2, p. 111-130, 2002.

BROWN, J. R.; WILCOX, D. W. Discounting State and Local Pension Liabilities. American Economic Review, v. 99, n. 2, p. 538-542, 2009.

CAETANO, M. A. R. Subsídios cruzados na previdência social brasileira. Brasília: Ipea, 2006. (Texto para discussão, 1211).

COMPRIX, J.; MULLER, K. A. Pension plan accounting estimates and the freezing of defined benefit pension plans. Journal of Accounting and Economics, v. 51, n. 1-2, p. 115.

FISHER, W. H.; KEUSCHNIGG, C. Pension reform and labor market incentives. Journal of Population Economics, v. 23, n. 2, p. 769-803, 2010.

FORTEZA, A.; OURENS, G. Redistribution, insurance and incentives to work in Latin American pension programs. Journal of Pension Economics and Finance, v. 11, n. 3, p 1-28, 2012.

FORTEZA, A.; OURENS, G. How much do Latin American pension programs promise to pay back? SP Discussion Paper, n. 0927, World Bank, 2009. 
GIAMBIAGI, F; AFONSO, L. E. Cálculo da alíquota de contribuição previdenciária atuarialmente equilibrada: uma aplicação ao caso brasileiro. Revista Brasileira de Economia, v. 63, n. 2, p. 153-179, 2009.

GUSTMAN, A. L.; STEINMEIER, T. L.; TABATABAI, N. Redistribution under the Social Security benefit formula at the individual and household levels, 1992 and 2004. Journal of Pension Economics and Finance, v. 12, n. 01, p. 1-27, 2012.

HASSLER, J.; LINDBECK, A. Optimal actuarial fairness in pension systems: a note. Economics Letters, V. 55 , n. 2 , p. $251-255,1996$.

IBRAHIM, F..Z. Desaposentação o Caminho Para Uma Melhor Aposentadoria. 5a Ed. Niteroi: Impetus, 2011

QUEISSER, M; WHITEHOUSE, E. Neutral or fair: actuarial concepts and pension-system design. OECD Social, Employment and Migr. Working Paper n. 40, 2006.

REZNIK, G. L.; WEAVER, D. A.; BIGGS, A. G. Social security and marginal returns to work near retirement. Social Security Issue Paper n. 2009-02, 2009.

SHOVEN, J. B.; SLAVOV, S. N. The decision to delay social security benefits: theory and evidence. NBER Working Paper No 17866, February, 2012a.

SHOVEN, J. B.; SLAVOV, S. N. When does it pay to delay social security? The impact of mortality, interest rates, and program rules. NBER Working Paper No 18210, July, 2012b.

SCHRÖDER, C. Profitability of pension contributions - evidence from real-life employment biographies. Journal of Pension Economics and Finance, v. 11, n. 3, p. 311-336, 2012.

VAN DUIJN, M.; MASTROGIACOMO, M.; LINDEBOOM, M.; LUNDBORG, P. Expected and actual replacement rates in the pension system of the Netherlands: how and why do they differ? Journal of Pension Economics and Finance, v. 12, n. 02, p. 168-189, 2013. 